\title{
Transformation Strategy of Foreign Trade Growth Mode in Jiangxi: Based on Low-Carbon Economy
}

\author{
Min Dai ${ }^{1}$, Meiling $\mathrm{Hu}^{2}$, Yuhong $\mathrm{Li}^{\mathbf{3}^{*}}$ \\ ${ }^{1}$ Jinggangshan University, Ji'an, China \\ ${ }^{2}$ International Business and Trade, Jilin University of Finance and Economics, Changchun, China \\ ${ }^{3}$ College of Economy and Management, Anqing Normal University, Anqing, China \\ Email: ${ }^{*}$ liyuhong0718@hotmail.com
}

Received 20 December 2013; revised 19 January 2014; accepted 14 February 2014

Copyright ( 2014 by authors and Scientific Research Publishing Inc.

This work is licensed under the Creative Commons Attribution International License (CC BY). http://creativecommons.org/licenses/by/4.0/

(c) () Open Access

\begin{abstract}
This work analyzes the advantages and disadvantages of developing low-carbon economy of Jiangxi province using the theory of trade and environment, and puts forward macro ideas and strategies to develop low-carbon economy and promote transformation of foreign trade growth mode of Jiangxi province from the system construction, element reserves, industrial layout, implementation approaches, and ways of developing low-carbon economy. Relying on the unique ecological advantages, the growth of foreign trade can be prompted to transfer from extensive mode to low-carbon green development and realize the strategy goal of Ecological province and Green development through developing low-carbon economy.
\end{abstract}

\section{Keywords}

Jiangxi; Low-Carbon Economy; Foreign Trade; Economic Growth

\section{Introduction}

About resources and environment, developed countries of industrialization tend to have a more profound understanding and a more intense sense of crisis, and the government also pays more attention to the problems of balance between economic development and resources and environment. Nowadays, a steady stream of goods is exported to Western countries from China, quite a lot of western scholars study the influence of trade on resources and environment. Some hold the view that trade has negative impact on resources and environment,

\footnotetext{
${ }^{*}$ Corresponding author.
} 
trade liberalization leads to energy crisis and environmental degradation directly, especially in developing countries that have loose environment policy. Some like Daly and Goodland (1993) believe that unrestricted free trade will increase the total output in the world and meanwhile damage the ecological environment.

The negative impact of trade on the environment tends to be greater in those countries of imperfect environmental policy. To pursue maximum profit, circumvent stringent environmental policy, and reduce the production costs of pollution-intensive industries, manufacturers will definitely transfer these industries to developing countries of loose environment policy, thereby, the environment is seriously contaminated in these countries or regions, and further affecting the global environment [1]. Chilchilnisky (1994) believes that in comparison with developing countries at the certain sewage prices, developed countries consume more environment resources because of lack of effective definition on private property, thus, trade liberalization will accelerate environmental damage in developing countries, and then pose a threat to the global environment [2]. Some scholars have proposed the eco-dumping issue of developed countries made by developing countries, and point that low-cost environmental standards force developing countries to generate a distorted cost and competitive advantages of trade, whereas developed countries are in an adverse competitive position and constitute the eco-dumping issue. This point becomes the theoretical basis of implementing green trade barriers.

Others hold the view that the influence of trade on resources and environment does more good than harm. Trade liberalization is not the source of environmental damage, and should not take the means of restricting trade to improve the environment; what's more, the damage of trade to the environment is only a short-term phenomenon. In the long run, the improvement of environment for trade liberalization will surely exceed its pollution effect through the measures of rational use of resources, division of labor specialization and technology improvement. Porter Hypothesis, a representative theory, suggests that, despite the fact that stringent environmental regulations increased production costs, it may also stimulate the motive of business innovation and technological innovation activities, and environmental policy also enables enterprises to get some revenue from recycling, and encourages enterprises to improve their efficiency, and enables them to gain a range of competitive advantages, and compensate for the cost losses from environmental policy to enterprises. Grossman and Krueger proposed the structure effect of the influence of trade on environment, that is, environmental pollution will change with the structure of outputs [3]. As the theory of comparative advantage, resources in trading countries are allocated in the sectors with comparative advantages to obtain scale economy, specialized division of labor in trading countries will help improve production efficiency, leading to an overall improvement of social welfare. Whereas as for a particular country, if the pollution-intensive industries have comparative advantages, the ecological environment will deteriorate with the expansion of trade liberalization; if the cleaning production industries have comparative advantages, the ecological environment of the country will get improved with the expansion of trade liberalization. Consequently, whether the impact of structure effect on environment is positive or not, depends on the average pollution levels of industries of comparative advantages.

\section{Develop Low-Carbon Economy, and Transfer the Growth Mode of Foreign Trade}

Based on the above theoretical views, we can see that trade makes the production apart from consumption; developed countries tend to transfer industries of higher environmental costs to developing countries of looser environment policy. With the continuous expansion of trade, trade structure of high emissions and high pollution in developing countries will exacerbate the deterioration of ecological environment, and accelerate energy shortages, and finally result in immiserizing growth. Therefore, transferring the foreign trade growth mode of high carbon emissions is the key to sustainable development in Jiangxi.

\subsection{Extensive Growth Mode of Foreign Trade Is Unsustainable under the Double Constricts of Resources and Environment}

In recent years, foreign trade growth in Jiangxi maintained double-digit growth, which is higher than the national average growth rate. But the growth of foreign trade depended on excess output of environment and resources; the foreign interest is at the high cost of large resources and environmental consumption. Statistics show that the major export products of Jiangxi in 2009 consisted of the eight main merchandise exports of steel, mechanical and electrical products, tungsten and its compounds, rare earth, primary textiles and clothing, footwear, paper and paperboard, and plastic product is up to $\$ 4.376$ billion, which accounts for $59.4 \%$ of total exports in Jiangxi 
province. These exports are mostly of high pollution resources consumptions, or labor-intensive low-end products, which are low in technical content and added value. Despite the development of foreign trade will bring some capital accumulation and technological progress, and promote economic development in Jiangxi to some extent, while this extensive foreign trade growth mode has generated larger resource and environmental pressures on Jiangxi Province in the middle of its industrialization. If this extensive economic growth mode continues, the comparative advantages of low-cost products in Jiangxi Province will soon disappear, and further lose its international competitiveness for the apparent lack of resources and rise of labor costs, and the extensive growth of high pollution and high emissions will further weaken the original ecological advantages of Jiangxi province, and the economic growth will be immiserizing.

\subsection{Developing Low-Carbon Economy Is the Main Way of Sustainable Development of Foreign Trade}

According to the UN definition, the sustainable development of trade is not only the continued growth of the total foreign trade and the enhancement of foreign trade structure as well as its quality, but also the coordinated development of trade, resources, environment, population, society and other aspects. Only concerning with trade volume but ignoring resources, environmental impact is a short-sighted economic development and it is unsustainable. Economic development model of low energy consumption, low pollution, low emissions aims at reducing the dependence on natural resources, and gets supported by sustainable use of energy, and focus on ecological and environmental protection in the process of development, thus it is sustainable. Green trade system has been built in Jiangxi, and the development of low-carbon industries sought through ecological advantages, and ecological protection is promoted through low-carbon economy, the positive interaction can complement each other, and form a win-win situation of trade, resources, environment and society.

\subsection{Low-Carbon Economy Is an Important Weight to Reverse the Disadvantages in Jiangxi}

From aspects of domestic and international macroeconomic environment, development of low-carbon economy is the trend. At present, the low-carbon economy of China is still in the initial exploratory stage, provinces have not formed an effective initiative of low-carbon economic development basically, and complete low-carbon chain has not been established, the effect driven by local economy has not yet fully revealed. Jiangxi has excellent ecological environment, and the total volume of industry is small, and it's the same to the stock of carbon industry, now the high-carbon industries are faster transferring to low-carbon industries, and has certain comparative advantages in developing low-carbon economy. Our Traditional manufacturing industry was relatively backward in the past, facing a new wave of the development of low-carbon economy, the pilot in low-carbon economy of Jiangxi province will bring about a new economic growth point, and form first-mover advantage in low-carbon economy, it will reverse the disadvantages of economy in Jiangxi, which falls behind other developed coastal provinces, and further strengthen the ecological advantages, and realize the carry catch of economy in China [4]. Developing low-carbon economy and transferring the growth mode of foreign trade match the strategic objectives of ecological province and green development, and truly realize the dreams of both gold and silver mines and green hills as well as clean waters.

\section{Analysis of Current Low-Carbon Economic Development in Jiangxi}

\subsection{Comparative Advantages of Developing Low-Carbon Economy}

Firstly, governments always try to strengthen Jiangxi province with strong environmental awareness. The idea of ecological province and green development is put forward, being homologous to low-carbon economy, both of them target at pursuing the harmony of economic development and environmental protection. The ecological and environmental protection started earlier in Jiangxi, provincial governments have been practicing the concept of low-carbon and environmental protection to achieve the economic goals of ecological province and green development, from the management projection of Mountain Lakes in the 80's last century to the construction of Poyang Lake Ecological Economic Zone this century, the ecological advantage of Jiangxi is gradually standing out, the forest coverage of Jiangxi is up to $63.1 \%$, forest carbon sinks is in the forefront of China; as the largest 
freshwater lake, Poyang Lake is the only large one that is not contaminated in China; there are 156 nature reserves in Jiangxi, and the ecological environment is overall well.

Secondly, low-carbon industry has a certain basis. In recent years, the development of low-carbon economy was implemented and developed surrounding Poyang Lake Ecological Economic Zone in Jiangxi province, and Nanchang becomes the first national low-carbon pilot city; it's initially succeeded in constructing Poyang Lake Ecological Economic Zone as a model, and an organic unity of Economic civilization and ecological civilization and social civilization has been presented in Komsomolsk; Pingxiang, Jingdezhen, Nanchang, Xinyu, Yingtan, Shangrao have been listed as the six pilot cities or districts of being resource-exhausted in transition, low-carbon economic development, energy conservation and other relevant reforms. Jiangxi has established ten key major areas to develop high-tech industries, such as photovoltaic materials, wind and nuclear energy, clean cars and motive power batteries, aerospace manufacturing, semiconductor lighting, new metal materials, on-metallic new materials, biology and new medicine, modern agriculture and green food, culture and creation, to actively optimize the energy structure while optimizing the industrial structure, and to develop clean renewable energy, like wind power, solar power, photovoltaic industry, natural gas, biomass and nuclear power. Currently, PV industry has been an important mainstay industry in Jiangxi, it has brought about a stable revenue growth of 50\%, the total revenue of PV industry was 81 billion RMB in 2010 (see Figure 1). There have been 14 wind farms, they have been the good basis for building green Jiangxi [5].

In addition, in comparison with the eastern developed provinces, the economy scale is much smaller in Jiang$\mathrm{xi}$, and the stock of backward production capacity is relatively small, and of course the transition cost is relatively lower, which also has become a potential advantage to develop low-carbon economy in Jiangxi.

\subsection{Constraints to Develop Low-Carbon Economy}

Although the development of low-carbon economy in Jiangxi has certain advantages, it is still in initial stage, there are still many constraints and obstacles to realize sustainable development:

Firstly, the supporting policy of the government is imperfect; low-carbon economic development lacks effective supporting system. Low-carbon economy is a system including the use of clean energy and the application of industrial low-carbon technologies, and low-carbon derivative markets as well, such as carbon trading market, carbon finance markets etc.; if we want low-carbon economy to become a major engine of economic growth in Jiangxi, we need right policies and regulations to guide specification and perfect regulatory system, a technology service platform, trading platform, and information exchange platform etc.; so as to make sure the low-carbon economy develops at a high starting point, and more orderly, and it must be standardized. However, there is not a perfect legislation system about low-carbon economy till now, and there are still legal gaps in some important areas and key links. Since 2011, Jiangxi Mining Environmental Management and Ecological Restoration Margin Interim Measures was enacted, and carried out an ecological compensation as experimental unit at Yuan River, and Poyang Lake Ecological Economic Zone Environmental Protection Regulations as well as Jiangxi Wetland Ordinance followed; but the legal norms involving a low-carbon economy is too macroscopic, empty and obscure with big flexibility to operate. Meanwhile, the construction of other supporting platforms is also backward; the mechanism of carbon emissions measurement and test and carbon emissions trading market could not be built, resulting in a worse effect of the market mechanism as a way to solve greenhouse gas emission, which has seriously impacted on the marketization of low-carbon economy.

Secondly, low-carbon economy cannot be assured for capital deficiency, technology and talent lack, and other factors. As the most important and fundamental factors of production, capital, technology and talents are inter-

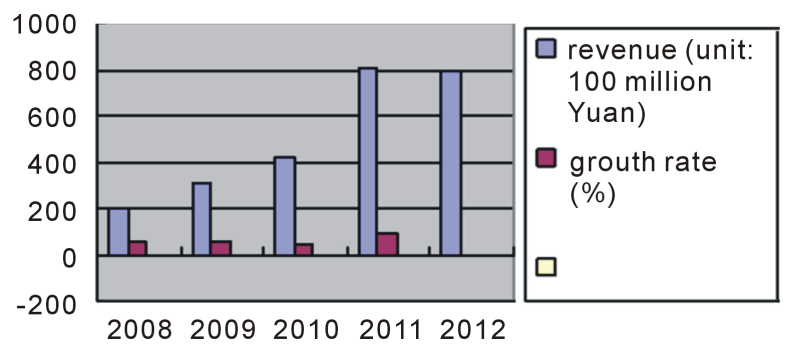

Figure 1. Revenue and Growth of PV Industry (2008-2012). 
related and interdependent. The key to develop low-carbon economy is low-carbon technology, and low-carbontechnology needs relevant technical talents and capital investment. In 2011, the expenditure in research and experimental development of Jiangxi was only 9.68 billion Yuan, and only accounted for $1.12 \%$ of that of China; Accepted patent applications are 2788 units throughout the year, only accounted for $0.17 \%$ of that of China. Meanwhile, the short-term returns of low-carbon economy was not significant, and the long-term gains is uncertain, companies don't have strong willingness to invest in low-carbon economy, and carbon credit financing system is imperfect, shortage in low-carbon developing funds becomes the biggest bottleneck that influences the development of low-carbon economy.

Thirdly, the existing industrial structure and energy consumption structure seriously restrict the development of low-carbon economy. In the traditional model of economic development, agricultural and industrial emit more carbon dioxide. From the regional composition of GDP changing situation of Jiangxi over the years, we can see that service industry occupied a lower proportion, the primary and secondary industries accounted for more than $65 \%$ of GDP. Although the proportion of primary industry in Jiangxi decreased significantly in recent years, the proportion of tertiary industry increased, however, the proportion of secondary industry increased steadily, accounting for more than half of GDP. The economic growth in Jiangxi mainly relies on secondary industry of carbon emissions, what's more, heavy chemical industry is serious, and heavy industry accounted for more than $60 \%$ of GDP (see Table 1). This kind of economic structure needs large consumption of resources and environment, but this kind of industrial pattern is difficult to get improved in short term during the course of high-speed of industrialization and urbanization in Jiangxi.

From the total energy production and consumption structure situation, we can see that energy sector excessively depends on coal of carbon emissions in Jiangxi. In 2010, raw coal production accounted for $86.1 \%$ of one energy structure. In energy consumption structure, coal, crude, hydropower are the main sources of energy consumption in Jiangxi Province. Coal and crude together accounted for $88.1 \%$ of non-renewable energy sources, and coal accounted for $70 \%$ of total energy consumption, hydropower of clean energy accounted for nearly $10 \%$ (see Table 2). Dependent inertia of energy consumption decided the difficult transition process of developing low-carbon economy in Jiangxi.

\section{Strategy of Developing Low-Carbon Economy}

Relying on low-carbon economy, Jiangxi province can promote the transformation from high pollution and high carbon emissions to clean and green growth mode of foreign trade growth in the regional economy development,

Table 1. Proportion of industry in GDP (2000-2010) (\%).

\begin{tabular}{|c|c|c|c|c|c|c|c|}
\hline & 2000 & 2005 & 2006 & 2007 & 2008 & 2009 & 2010 \\
\hline Primary industry & 24.2 & 17.9 & 16.8 & 16.4 & 15.2 & 14.4 & 12.8 \\
\hline Second industry & 35.0 & 47.3 & 50.2 & 51.7 & 51 & 51.2 & 54.2 \\
\hline Tertiary industry & 40.8 & 34.8 & 33.0 & 31.9 & 33.8 & 34.4 & 33.0 \\
\hline Light industry & 37.7 & 34.6 & 32.5 & 32.4 & 34 & 33.6 & 34.6 \\
\hline Heavy industry & 62.3 & 65.4 & 67.6 & 67.6 & 66 & 66.4 & 65.4 \\
\hline
\end{tabular}

Data: China Jiangxi Statistic Yearbook (2011).

Table 2. Energy composition (2006-2010) (\%).

\begin{tabular}{|c|c|c|c|c|c|c|}
\hline \multirow{2}{*}{ Year } & \multicolumn{3}{|c|}{ Production } & \multicolumn{3}{|c|}{ Consumption } \\
\hline & Raw coal & Natural gas & Hydro power & Raw coal & Natural gas & Hydro power \\
\hline 2006 & 83.5 & 0.1 & 16.4 & 73.2 & 0.2 & 8.0 \\
\hline 2007 & 87.2 & 0.3 & 12.5 & 75.9 & 0.3 & 5.6 \\
\hline 2008 & 87.0 & 0.2 & 12.8 & 73.7 & 0.6 & 5.7 \\
\hline 2009 & 89.1 & 0.2 & 10.7 & 73.8 & 0.5 & 4.7 \\
\hline 2010 & 86.1 & 0.2 & 13.7 & 74.4 & 1.0 & 4.8 \\
\hline
\end{tabular}

Data: China Jiangxi Statistic Yearbook (2011). 
the government should determine macro ideas and strategies to develop low-carbon economy on the basis of institutional plan, factor stockage, industrial layout, and approaches or means of implementation.

\subsection{Strengthen Policy Guiding to Establish and Improve the Institutional Support System of Low-Carbon Economy}

The emerging industries can't develop and rise without policy support and government guidance. The chief task is to innovate the institutional system, and to get rid of the systematic defects to develop low-carbon economy in the process of transformation mode and urban development model, then the thinking inertia or practices of only focusing on corporate profit but not environmental and ecological status [6]. Only forming the institutional support system of low-carbon industry development, can we offer motive and security for building low-carbon industries, and low-carbon economy has the institutional security for its sustainable development: 1) Establish a sound regulation and policy system about low-carbon economy. Under the framework of national laws and regulations, we can combine the current regulations and administrative provisions on the ecological and environmental protection as well as energy conservation or etc., to improve the policies and regulations further, to guide and regulate the development of low-carbon industries. We must focus on complementing and improving energy legislation and incentives to develop and apply low-carbon technologies, and formulate local administrative regulations being in favor of emissions of greenhouse gas, and improve the development and utilization of clean and low-carbon energy, and promote the research and development of clean energy. Meanwhile, regulations and standard systems of resources conservation and environment protection of Jiangxi province should be improved to stimulate the self-innovation of low-carbon technologies, and lead the development of low-carbon economy to the track of legal protection; 2) establish both the incentive and restrictive fiscal policy. Making use of fiscal policy which has the function of macro-control to encourage enterprises to carry out energy conservation initiatively, and actively complete low-carbon technology innovation. Preferential policies finance and taxes are given to those enterprises who meet carbon emission standards. Learn from foreign experience, trial implementation of carbon tax or similar environmental taxes for super emitters will link carbon emissions with tax revenue, and pull open the difference of tax burden of using different energy resources, thus, different energy use and energy efficiency will directly impact corporate tax, and affect corporate profits, and enable enterprises to consciously use low-carbon energy to reduce carbon emissions, and to further achieve the effect of low-carbon production; 3) Improve the investment and financial system of developing low-carbon economy. Transformation of high-carbon industries to low-carbon industries needs some start-up costs, for the lack of effective risk compensation and security; it often leads to more operating costs of transformation enterprises substantially and lower profitability. Governments should fully play roles in macro-guidance to establish loan scale guide policy associated with energy conservation project, and make sure that credit and loans of financial institutions inclines to the fields and industries meeting CDM gradually to promote the development of low-carbon economy.

\subsection{Attract Talents and Investments from Overseas, and Establish Factors Reservation of Low-Carbon Economy for Sustainable Development}

Recently, the shortage of factors is obvious in the development of low-carbon economy of Jiangxi province, lack of capital and brain drain have restricted the development of low-carbon economy; therefore, the government should actively build a platform to attract talents and investments from overseas to meet the needs of low-carbon economy. Therefore, government guarantee mechanism of low-carbon economic credit should be established accordingly to encourage and guide private capital to participate in investment and construction of low-carbon projects consciously; Support enterprises of low-carbon activities to finance through bonds to solve problem of innovative funding gap of low-carbon technologies. Establish intermediary service platform for CDM project consultancy, and help enterprises to know CDM projects to encourage and assist them to cooperate with foreign CDM projects actively; the core of CDM allows both developed and developing countries to transfer and acquire the offset amount of reducing emissions, developed countries can acquire reduced emissions from developing countries through CDM projects, and can reduce costs and fulfill the obligation of reducing emissions, while developing countries can obtain capital and technologies of reducing emissions from developed countries, and can resolve financial and technical shortages of low-carbon economy. In order to attract talents, Jiangxi province should formulate talents import policy of emerging strategic industries, and develop preferential poli- 
cies of importing super talents. Meanwhile, employ talents of low-carbon economy and environmental technologies via low-carbon project, and organize people to train abroad to reserve intelligence for the low-carbon economy. Establish school-enterprise research institutes and collaborative innovation platform to promote research and practice of low-carbon economy.

\subsection{Scientifically and Reasonably Plan Key Fields and Industries of Low-Carbon Economy}

Developing low-carbon economy is to decrease emissions of greenhouse gas, and construct low energy consumption, and low pollution-based economic system, including low-carbon energy systems, low-carbon technologies and low-carbon industrial system. Low-carbon economy covers widely, but it can not effect in all aspects, it can operate by combining all the advantages of regional factor endowments, and determine the key areas and pilot industries to be more bigger and stronger by focusing on elements, and improve the related low-carbon industrial chain, and make the key areas and key industries more competitive in the first-mover advantage process of strengthening continuously in Jiangxi.

Industry is responsible for high-carbon emissions, so the acting point of transformation is industry, energy structure should be optimized actively, and key industries should be arranged. Energy layout, in Jiangxi, mainly focuses on the solar power, biomass power, wind power, and nuclear power. Currently, clean energy with pilot advantages includes solar photovoltaic industry, biomass power, wind power, and nuclear power. Therefore, we can mainly develop clean energy continuously in substitute for fossil fuels of high pollution, and optimize energy structure of Jiangxi. As an industrial arrangement, we should highlight the advantages and characteristics with the existing basis and conditions in Jiangxi, and mainly foster the emerging strategic industries including solar power representing new energy and biomedicine to establish the emerging industrial system with the core of low-carbon agriculture, low-carbon industry, and service industry. Vigorously promote technological innovation of low-carbon and ecological economy at the same time, upgrade traditional industries relying on advanced practical technologies to maximize the resources productivity and energy efficiency.

\subsection{Construct an Economic Network of Low-Carbon through Reducing Carbon Emissions and Increasing Carbon Sequestration}

Both carbon reduction and carbon sinks can result in green rising in Jiangxi. Carbon reduction is mainly approached by optimizing energy structure, building a low or even zero carbon industries, and promoting the use of low-carbon technologies to promote industrial transformation of high-carbon ones. Increasing carbon sinks refers to the increasement of carbon deposit bodies in nature. As forests including plantations can absorb plenty of carbon dioxide in the atmosphere through photosynthesis, and mitigate the greenhouse effect. Therefore, forest carbon sinks is the largest carbon stock of terrestrial ecosystem, and it has a very unique role in reducing concentrations of greenhouse gases in the atmosphere and mitigating global climate warming. When developing low-carbon economy, Jiangxi province should pay more attention to the construction of carbon sinks. Continue to promote one-big and four-small project to mobilize more enterprises and social forces to plant trees, improve the greening rates of cities, villages, mines, and industrial parks; expand the economic areas planting trees, and generalize plantation of industrial raw materials trees, like light skin trees, pine trees, fruit trees and so on to expand carbon sink forest while expanding the supply of raw materials of related industries, enhance the stamina of industrial development, and consequently forests become the green bank in Jiangxi province.

\subsection{Strengthen the Cooperation with Partners at Home and Aboard to Actively Participate in the Matters Related to Low-Carbon Economy}

Jiangxi should actively practice and understand foreign policy of low-carbon economy and relevant market mechanism aboard, learn from the experience of low-carbon economy at home and aboard, and explore the framework and strategies of low-carbon economy in this region [7]. Make full use of market mechanism to promote the implementation of Clean Development Mechanism project, and encourage enterprises to develop the construction of CDM project in areas of hydropower, wind power, landfill, and coal bed methane utilization, and low temperature waste heat power generation. Vigorously importing and accepting advanced energy-saving technologies, and vigorously attracting domestic and foreign investors of photovoltaic products, lithium power, 
wind power, nuclear power, natural gas, and waste disposal as well jointly promote the development of low-carbon and ecological economy.

\section{Acknowledgements}

This paper is financially supported by the projects Study on the Transformation Strategy of Foreign Trade Growth Mode in China Jiangxi-Based on the Perspective of Low Carbon Economy (ID: JJ1232).

\section{References}

[1] Daly, H. and Goodland, R. (1993) An Ecological Assessment of Deregulation of International Commerce under GATT. Ecological Economics, 9, 73-92. http://dx.doi.org/10.1016/0921-8009(94)90017-5

[2] Chilehilnisky (1994) North-South Trade and the Global Environment. American Economic Review, 84, 851-874.

[3] Grossman and Krueger (1991) Environmental Impacts of a North America Free Trade Agreement. NBER Working Paper, NO. 3914.

[4] Dai, M. and Zuo W.J. (2012) Promoting the Integration of Low-Carbon Economy and Foreign Trade Growth Pattern: Case of Jiangxi Province. Science and Technology Management Research, 8, 84-87.

[5] Li, M. (2011) Trade Pattern and the Plight of China’s Low Carbon Economy. Fujian Tribune, 5, 38-41.

[6] Gao, J.-S. (2011) SWOT Analysis and Related Strategies of Developing Low-Carbon Economy in Poyang Lake Eco-Economic Region. Journal of Xinyu University, 4, 4-7.

[7] Li, Y.Z. (2011) Transformation of the Mode of Economic Development Based on the View of Low-Carbon Economy. Academic Journal of Shanxi Provincial Committee Party School of C.P.C., 10, 101-105. 